\title{
Costs and healthcare utilisation of patients with heart failure in Spain
}

\author{
Carlos Escobar ${ }^{1 *}$ (D), Luis Varela², Beatriz Palacios², Margarita Capel ${ }^{2}$, Antoni Sicras $^{3}$, Aram Sicras $^{3}$, Antonio Hormigo $^{4}$, \\ Roberto Alcázar ${ }^{5}$, Nicolás Manito ${ }^{6}$ and Manuel Botana ${ }^{7}$
}

\begin{abstract}
Background: Increasing the knowledge about heart failure (HF) costs and their determinants is important to ascertain how HF management can be optimized, leading to a significant decrease of HF costs. This study evaluated the cumulative costs and healthcare utilisation in HF patients in Spain.
\end{abstract}

Methods: Observational, retrospective, population-based study using BIG-PAC database, which included data from specialized and primary care of people $\geq 18$ years, from seven autonomous communities in Spain, who received care for HF between 2015 and 2019. The healthcare and medication costs were summarized on a yearly basis starting from the index date (1st January 2015), and then cumulatively until 2019.

Results: We identified 17,163 patients with HF (year 2015: mean age $77.3 \pm 11.8$ years, 53.5\% men, 51.7\% systolic HF, 43.6\% on NYHA functional class II). During the 2015-2019 period, total HF associated costs reached 15,373 Euros per person, being cardiovascular disease hospitalizations the most important determinant (75.8\%), particularly HF hospitalizations (51.0\%). Total medication cost accounted for $7.0 \%$ of the total cost. During this period, there was a progressive decrease of cardiovascular disease hospital costs per year (from 2834 Euros in 2015 to 2146 Euros in 2019, $P<0.001)$, as well as cardiovascular and diabetic medication costs.

Conclusions: During the 2015-2019 period, costs of HF patients in Spain were substantial, being HF hospitalizations the most important determinant. Medication costs represented only a small proportion of total costs. Improving HF management, particularly through the use of drugs that reduce HF hospitalization may be helpful to reduce HF burden.

Keywords: Heart failure cost, Dapagliflozin, DAPA-HF, Heart failure, Hospitalization, Sacubitril/valsartan

\section{Background}

Heart Failure (HF) is a complex clinical syndrome caused by structural or functional cardiac alterations, leading to a reduced cardiac output or elevated intracardiac pressures at rest or during stress, that cause the typical symptoms such as breathlessness, or fatigue $[1,2]$. HF is a growing problem worldwide [3]. It has been estimated that the prevalence of $\mathrm{HF}$ is around $2 \%$ of the adult population in developed countries, raising to more than $10 \%$ in those

\footnotetext{
* Correspondence: escobar_cervantes_carlos@hotmail.com

${ }^{1}$ University Hospital La Paz, Madrid, Spain

Full list of author information is available at the end of the article
}

individuals aged 70 years or older [4]. In Spain, it has been reported a higher prevalence of $\mathrm{HF}$, reaching $5 \%$ in some studies [5, 6]. Of note, it is expected that the prevalence of HF will increase in the following years, mainly due to the ageing of the population, the rise in HF risk factors (i.e. hypertension, diabetes) and the better treatment of acute cardiovascular events [3].

Despite traditional HF therapies (i.e renin angiotensin system inhibitors, beta blockers and aldosterone antagonists), mortality and hospitalization rates remain unacceptably high $[7,8]$. Thus, the MAGGIC meta-analysis that included individual data on 39,372 patients with

C C The Author(s). 2020 Open Access This article is licensed under a Creative Commons Attribution 4.0 International License, which permits use, sharing, adaptation, distribution and reproduction in any medium or format, as long as you give appropriate credit to the original author(s) and the source, provide a link to the Creative Commons licence, and indicate if changes were made. The images or other third party material in this article are included in the article's Creative Commons licence, unless indicated otherwise in a credit line to the material. If material is not included in the article's Creative Commons licence and your intended use is not permitted by statutory regulation or exceeds the permitted use, you will need to obtain permission directly from the copyright holder. To view a copy of this licence, visit http://creativecommons.org/licenses/by/4.0/ The Creative Commons Public Domain Dedication waiver (http://creativecommons.org/publicdomain/zero/1.0/) applies to the data made available in this article, unless otherwise stated in a credit line to the data. 
HF, from 30 cohort studies showed that $40.2 \%$ of patients died after 2.5 years of follow-up [8]. However, in the last years, the PARADIGM-HF and more recently, the DAPA-HF trials have shown that sacubitril/valsartan and dapagliflozin, respectively, have a positive impact on morbidity and mortality among patients with HF and reduced left ventricular ejection fraction $[9,10]$.

Remarkably, HF represents a major and growing economic problem $[3,11,12]$. Studies particularly focused on HF economic burden are important as they contribute to a better understanding of the drivers and problems which may lead to the increasing HF costs [3]. Increasing the knowledge about HF costs and their determinants is important in order to ascertain how HF management can be optimized, leading to a significant decrease of HF costs $[3,7,11,12]$. Unfortunately, data about costs of HF in Spain are very scarce or limited to the use of specific drugs, but not focused on a comprehensive approach [13-18]. For example, a study performed in Spain in 2014 among only 374 patients reported a high total cost associated with HF [18]. As a result, new studies with a high number of patients that provide current data are warranted.

The aim of this study was to evaluate the cumulative costs and healthcare utilisation in HF patients in Spain over the last 5 years, along with the epidemiological characterization of the population at index date (1st January 2015). This was also analyzed in a population who met the most relevant inclusion criteria of the DAPA-HF trial [10] (DAPA-HF like population) with the aim of understanding the costs associated with the management of HF with reduced ejection fraction from the DAPA-HF trial population.

\section{Methods}

Observational cohort study, comprising cross-sectional and longitudinal retrospective analyses using secondary data captured in electronic health records from seven Spanish regions. Data sources were provided by BIG$\mathrm{PAC}^{\circ}$. BIG-PAC is an electronic database that integrate information from primary and specialist care medical records. This database has been validated as an information source for studies of epidemiology, therapeutic adaptation and health/non-healthcare resource use and associated costs. It is representative of the Spanish population [19].

The HF population was defined as all patients $\geq 18$ years of age and with at least one diagnosis of HF prior to the index date (first January 2015). Type 2 diabetes (T2D) was defined as all patients $\geq 18$ years of age filling a prescription of any antidiabetic medication, T2D diagnosis or HbA1c $>7 \%$ prior to index date. The DAPA-HF like population included those patients $\geq 18$ years, with a HF history of more than 8 weeks, treatment with device therapy or standard HF treatment, NYHA class $\geq \mathrm{II}$ within 1 year prior to index date and left ventricular ejection fraction $\leq 40 \%$. Patients with HF hospitalization in the previous 4 weeks prior to index date, myocardial infarction, unstable angina pectoris, stroke, transient ischemic attack, coronary revascularization or implantation of therapeutic device $<12$ weeks prior to index date, were excluded from the population.

Comorbidities were searched for in all available data prior to index date, excepting for severe hypoglycemia that was considered only within 1 year before index date and cancer which was searched for up to 5-year prior to index date. A minimum of 1 year of data before index date was required. Comorbidities included cardiovascular disease (myocardial infarction, percutaneous or surgical revascularization, unstable angina, angina pectoris), HF, chronic kidney disease, atrial fibrillation, stroke (hemorrhagic, ischemic, transitory ischemic attack), peripheral artery disease, major organ specific bleeding, microvascular complications (diabetic mono-/polyneuropathy, diabetic eye complications, diabetic kidney disease), severe hypoglycemia, cancer, chronic obstructive pulmonary disease, and lower limb complications. ICD-9 and ICD-10 codes (https://eciemaps.mscbs.gob.es) were considered for the diagnosis of comorbidities (supplementary Table 1).

The information about treatment was recorded from the registries for dispensing medicines, according to the Anatomical Therapeutic Chemical Classification System (supplementary Table 1) [20]. HF treatments (angiotensin-converting enzyme inhibitors, angiotensin receptor blockers, beta blockers, aldosterone antagonists, sacubitril/valsartan, loop diuretics, digoxin), warfarin, statins, aspirin, receptor P2Y12 antagonists, calcium channel blockers, thiazides, nitrates, antidiabetic medications (SGLT-2 inhibitors, metformin, sulfonylurea, DPP-4 inhibitors, GLP-1 receptor agonists, metiglinides, glitazones, acarbose, miglitol, insulin) were recorded. The prescription of a drug in a specific patient was based only on medical criteria (clinical practice).

Prevalence, incidence and baseline characteristics (total HF population and by T2D status), including demographics, comorbidities and medications were calculated at index date (first January 2015).

The healthcare resource use and costs and medication costs were summarized for the total HF population on a yearly basis starting from index date (first January 2015), and then cumulatively until the end of the last year of follow up (31st December 2019). All hospital visits (total and cardiovascular events), the number of medical visits and emergency room visits and medication costs (total, cardiovascular related, HF related and diabetes related) were included for the analysis of the annual direct healthcare costs. Patients who died during follow-up had 
a cost of 0 allocated to the remaining duration of the study, whereas a patient leaving the database prior to data cut off was not included in the denominator for the time after leaving the database. Annual indirect nonhealth costs included the number of days of productivity lost due to disability.

Rates were obtained from hospital accounting, except for the medication and indirect costs which were calculated as follows, respectively: a) medical prescriptions: according to the retail price per package at the time of dispensing [21]; b) costs for days of productivity lost: according to the mean interprofessional wage [22]. Hospital admission costs for cardiovascular events during follow-up were obtained taking into consideration daily hospital rate and number of hospital days per stay. Rates are summarized in supplementary Table 2.

\section{Statistical analysis}

Categorical variables were described by their absolute (n) and relative frequencies (\%). Continuous variables were described using the mean and standard deviation. Categorical variables were compared with the Chisquare test or the Fisher exact test when appropriate. When two means were compared, the $t$-student test was used. Analyses of health care cost were performed for the index date with 5 year of follow-up. The cumulative mean healthcare cost was estimated and presented on a yearly basis from the index date until last year of followup. Health care costs were presented per patient (mean cost). A level of statistical significance of 0.05 was applied in all the statistical tests. The data were analyzed using the statistical package SPSS v22.0 (SPSS Inc., Chicago, Illinois, USA).

\section{Results}

Out of 1,7 millions of persons included in the BIG-PAC ${ }^{\circ}$ database in 2015, 1,3 million people were attended during the 2012-2014 period, of whom 964,862 were 18 years or older. At index date, 17,598 patients had HF. As 435 patients were excluded due to inconsistent data, 17, 163 patients (1.78\%) comprised the HF study population (Fig. 1). Incidence at index date was $2.84 \times 1000$ patientyears.

The baseline clinical characteristics of the HF population according to the presence of T2D were presented in Table 1. Overall, mean age was $77.3 \pm 11.8$ years, $53.5 \%$ of patients were men, $51.7 \%$ of patients had reduced left ventricular ejection fraction $\mathrm{HF}$, and the majority of patients were on NYHA functional class II $(43.6 \%)$ or III (36.1\%). A total of 5815 (33.9\%) patients had T2D. The presence of other comorbidities was common: $30.0 \%$ of patients had atrial fibrillation, $29.5 \%$ chronic kidney disease, $23.3 \%$ ischemic heart disease, $17.2 \%$ chronic obstructive pulmonary disease, $12.8 \%$ cancer and $9.5 \%$

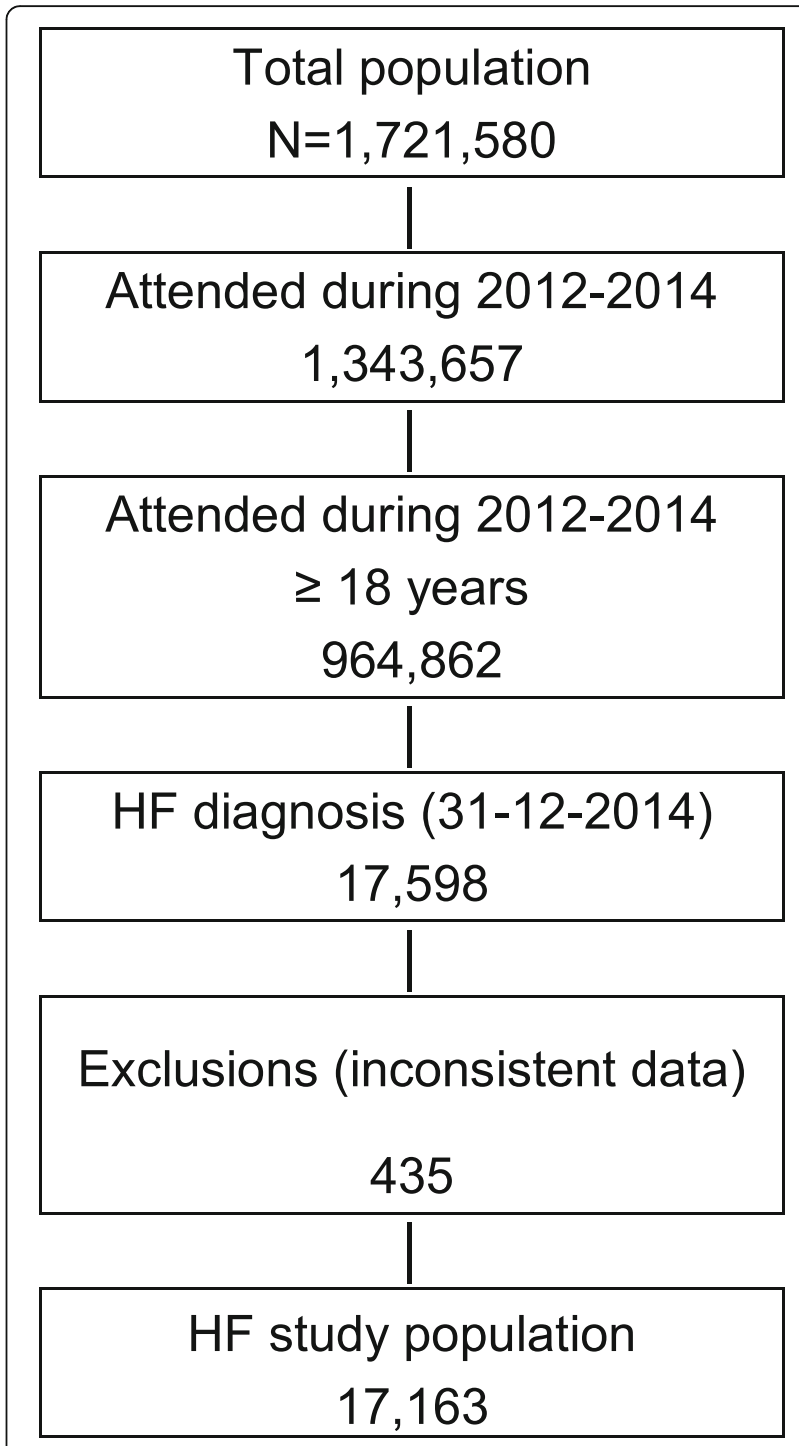

Fig. 1 Flowchart cost population (2015)

previous stroke. Two thirds of patients were taking renin angiotensin system inhibitors, $68.3 \%$ beta blockers, $30.0 \%$ aldosterone antagonists, and $8.5 \%$ sacubitril/valsartan. The baseline clinical profile of patients according to the presence of T2D was also compared. The percentage of patients with left ventricular ejection fraction $\leq 40 \%$ was higher in patients with type 2 diabetes $(53.1 \%$ vs $51.0 \% ; P=0.015)$. Those patients with $\mathrm{T} 2 \mathrm{Dd}$ had more ischemic heart disease, stroke, atrial fibrillation, peripheral artery disease, and chronic kidney disease, and a higher body mass index $(P<0.05$ or less for all comorbidities).

Patient hospital mean cost for year was presented in Table 2. In general, from 2015 to 2019, there was a progressive decrease of cardiovascular disease hospital cost per patient year (from 2834 to 2146 Euros, $P<0.001$ ). Overall, patient cumulative cardiovascular disease 
Table 1 Baseline clinical characteristics of the heart failure population at index date 1st January 2015 according to the presence of type 2 diabetes

\begin{tabular}{llll} 
No T2D $(\boldsymbol{n}=\mathbf{1 1 , 3 4 8 ;} \mathbf{6 6 . 1 \% )}$ & $\begin{array}{l}\text { T2D } \\
(\boldsymbol{n}=\mathbf{5 8 1 5} ; \mathbf{3 3 . 9 \%})\end{array}$ & $\begin{array}{l}\text { Total HF } \\
(\boldsymbol{n}=\mathbf{1 7}, \mathbf{1 6 3} ; \mathbf{1 0 0 \%})\end{array}$ & $\mathrm{P}^{*}$ \\
\hline $77.4 \pm 12.6$ & & & \\
$6308(55.6)$ & $77.2 \pm 10.1$ & $77.3 \pm 11.8$ & 0.236 \\
$6052(53.3)$ & $2648(45.5)$ & $8956(52.2)$ & $<0.001$ \\
$28.1(5.8)$ & $3135(53.9)$ & $9187(53.5)$ & 0,470 \\
$128.7 \pm 21.9$ & $29.5(6.0)$ & $28.6(5.9)$ & $<0.001$ \\
& $131.8 \pm 22.6$ & $129.8 \pm 22.2$ & $<0,001$
\end{tabular}

\section{Heart failure data}

NYHA functional class, n (\%)

I
III
IV
Left ventricular ejection fraction, \%
$\leq 40 \%, \mathrm{n}(\%)$
$>40-<50 \%, \mathrm{n}(\%)$
$\geq 50 \%, \mathrm{n}(\%)$

\section{Laboratory data}

$$
\mathrm{eGFR}, \mathrm{ml} / \mathrm{min} / 1.73 \mathrm{~m}^{2}
$$

$\mathrm{HbA} 1 \mathrm{C}, \%$

\section{Comorbidities}

\section{Cardiovascular disease, n (\%)}

$\begin{array}{ll}\text { Ischemic heart disease } & 2174(19.1) \\ \text { Myocardial infarction } & 1350(11.9) \\ \text { CABG } & 122(1.1) \\ \text { PCI with stent } & 285(2.5) \\ \text { Unstable angina } & 414(3.7) \\ \text { Angina pectoris } & 686(6.1) \\ \text { Stroke } & 1015(8.9) \\ \text { Ischemic stroke } & 779(6.9) \\ \text { Hemorrhagic stroke } & 72(0.6) \\ \text { Transitory ischemic attack } & 256(2.3) \\ \text { Atrial Fibrillation } & 3339(29.4) \\ \text { Peripheral artery disease } & 500(4.4) \\ \text { Chronic kidney disease } & 2819(24.8) \\ \text { Microvascular complications } & 0 \\ \text { Diabetic mono-/polyneuropathy } & 0 \\ \text { Diabetic eye complications } & 0 \\ \text { Diabetic foot/peripheral angiopathy } & 0 \\ \text { Diabetic kidney disease } & 0 \\ \text { Diabetes with complications } & 0 \\ \text { Severe hypoglycemia } & 0\end{array}$

$$
\begin{aligned}
& 1321(11,6) \\
& 5008(44.1) \\
& 4068(35.9) \\
& 395(3.5) \\
& 44.2 \pm 10.6 \\
& 5217(51.0) \\
& 801(7.8) \\
& 4217(41.2)
\end{aligned}
$$

$\begin{array}{lll}654(11.3) & 1975(11.5) & \\ 2476(42.6) & 7484(43.6) & 0.001 \\ 2135(36.7) & 6203(36.1) & \\ 268(4.6) & 663(3.9) & <0.001 \\ 41.5 \pm 12.4 & 43.3 \pm 11.3 & 0.012 \\ 2798(53.1) & 8015(51.7) & 0.012 \\ 428(8.1) & 1229(7.9) & 0.012 \\ 2039(38.7) & 6256(40.4) & \\ 72.3 \pm 20.4 & & <0.001 \\ 7.3 \pm 0.8 & 74.8 \pm 20.5 & <0.001\end{array}$

$76.1 \pm 20.4$

$7.3 \pm 0.8$

$6.1 \pm 1.4$

$<0.001$

$\begin{array}{lll}1834(31.5) & 4006(23.3) & <0.001 \\ 1126(19.4) & 2466(14.4) & <0.001 \\ 132(2.3) & 254(1.5) & 0.001 \\ 243(4.2) & 528(3.1) & <0.001 \\ 384(6.6) & 798(4.7) & <0.001 \\ 493(8.5) & 1179(6.9) & <0.001 \\ 622(10.7) & 1637(9.5) & <0.001 \\ 467(8.0) & 1246(7.3) & 0.005 \\ 28(0.5) & 100(0.6) & 0.213 \\ 173(3.0) & 429(2.5) & 0.004 \\ 1805(31.0) & 5144(30.0) & 0.029 \\ 326(5.6) & 826(4.8) & 0.001 \\ 2236(38.5) & 5055(29.5) & <0.001 \\ 1810(31.1) & 1810(10.5) & <0.001 \\ 380(6.5) & 380(2.2) & <0.001 \\ 1598(27.5) & 1849(10.8) & <0.001 \\ 251(4.3) & 264(1.5) & <0.001 \\ 468(8.1) & 521(3.0) & <0.001 \\ 3207(55.2) & 3452(20.1) & <0.001 \\ 461(7.9) & 461(2.7) & <0.001\end{array}$


Table 1 Baseline clinical characteristics of the heart failure population at index date 1st January 2015 according to the presence of type 2 diabetes (Continued)

\begin{tabular}{|c|c|c|c|c|}
\hline & No T2D ( $n=11,348 ; 66.1 \%)$ & $\begin{array}{l}\text { T2D } \\
(n=5815 ; 33.9 \%)\end{array}$ & $\begin{array}{l}\text { Total HF } \\
(n=17,163 ; 100 \%)\end{array}$ & $P^{*}$ \\
\hline \multicolumn{5}{|l|}{ Other comorbidities, n (\%) } \\
\hline Cancer & $1465(12.9)$ & $733(12.6)$ & $2198(12.8)$ & 0.572 \\
\hline Chronic obstructive pulmonary disease & $1928(17.0)$ & $1027(17.7)$ & $2955(17.2)$ & 0.270 \\
\hline Lower limb amputations & $37(0.3)$ & $108(1.9)$ & $145(0.8)$ & $<0.001$ \\
\hline Major organ specific bleeding & $111(1.0)$ & $177(3.0)$ & $288(1.7)$ & $<0.001$ \\
\hline \multicolumn{5}{|l|}{ Therapies } \\
\hline Heart failure medications, n (\%) & $11,348(100)$ & $5815(100)$ & $17,163(100)$ & - \\
\hline Renin angiotensin system inhibitors & $6973(61.5)$ & $4452(76.6)$ & $11,425(66.6)$ & $<0.001$ \\
\hline Angiotensin-converting enzyme inhibitors & 3354 (29.6) & $1986(34.2)$ & $5340(31.1)$ & $<0.001$ \\
\hline Angiotensin receptor blockers & 3619 (31.9) & $2466(42.4)$ & 6085 (35.5) & $<0.001$ \\
\hline Beta blockers & 7509 (66.2) & $4218(72.5)$ & $11,727(68.3)$ & $<0.001$ \\
\hline Loop-diuretics & $7416(65.4)$ & $4645(79.9)$ & $12,061(70.3)$ & $<0.001$ \\
\hline Aldosterone antagonists & $3424(30.2)$ & $1728(29.7)$ & $5152(30.0)$ & 0.537 \\
\hline Sacubitril/valsartan & $987(8.7)$ & $477(8.2)$ & $1464(8.5)$ & 0.272 \\
\hline Digoxin & $799(7.0)$ & $398(6.8)$ & $1197(7.0)$ & 0.632 \\
\hline \multicolumn{5}{|l|}{ Other cardiovascular medications, n (\%) } \\
\hline Low dose aspirin & $3017(26.6)$ & $2037(35.0)$ & $5054(29.5)$ & $<0.001$ \\
\hline Receptor P2Y12 antagonists & $1177(10.4)$ & $634(10.9)$ & $1811(10.6)$ & 0.284 \\
\hline Statins & $5928(52.2)$ & $3238(55.7)$ & $9166(53.4)$ & $<0.001$ \\
\hline Antihypertensives & $2415(21.3)$ & $1478(25.4)$ & $3893(22.7)$ & $<0.001$ \\
\hline Dihydropyridines CCB & $1564(13.8)$ & $1027(17.7)$ & $2591(15.1)$ & $<0.001$ \\
\hline Thiazides & $520(4,6)$ & $268(4,6)$ & $788(4.6)$ & 0,938 \\
\hline Non-hydropyridines CCB & $504(4,4)$ & $290(5,0)$ & $794(4.6)$ & 0,107 \\
\hline Nitrates & $1169(10,3)$ & $788(13,6)$ & $1957(11,4)$ & $<0,001$ \\
\hline Warfarin & $2438(21,5)$ & $1464(25,2)$ & $3902(22,7)$ & $<0,001$ \\
\hline Diabetes medications, n (\%) & 0 & $5383(92.6)$ & $5383(31.4)$ & $<0.001$ \\
\hline Metformin & 0 & $3862(66.4)$ & $3862(22.5)$ & $<0.001$ \\
\hline Sulfonylurea & 0 & 1952 (33.6) & $1952(11.4)$ & $<0.001$ \\
\hline DPP4 inhibitors & 0 & $1416(24.4)$ & $1416(8.3)$ & $<0.001$ \\
\hline SGLT-2 inhibitors & $1(0 \%)$ & $2(0)$ & $3(0)$ & $<0.001$ \\
\hline GLP-1 receptor agonists & 0 & $57(1.0)$ & $57(0.3)$ & $<0.001$ \\
\hline Metiglinides & 0 & $319(5.5)$ & 319 (1.9) & $<0.001$ \\
\hline Glitazones & 0 & $57(1.0)$ & $57(0.3)$ & $<0.001$ \\
\hline Acarbose & 0 & $88(1.5)$ & $88(0.5)$ & $<0.001$ \\
\hline Insulin & 0 & $1367(23.5)$ & $1367(8.0)$ & $<0.001$ \\
\hline
\end{tabular}

T2D Type 2 diabetes, HF Heart failure, eGFR Estimated glomerular filtration rate, $C A B G$ Coronary artery bypass graft, $P C I$ Percutaneous coronary intervention, $C C B$ Calcium channel blockers, DPP4 Dipeptidyl peptidase 4, SGLT-2 Sodium-glucose Cotransporter-2, GLP-1 Glucagon-like peptide-1

${ }^{*} p$ values comparing no T2D vs T2D

hospital mean cost reached 11,649 Euros in 2019 (supplementary Table 3 and Fig. 2). The great burden for this cost was due to cardiorenal (HF and/or chronic kidney disease) hospitalizations ( $88.8 \%$ of the total cost), particularly HF (67.3\% of the total cost). With regard to medication, from 2015 to 2019, diabetes medication mean cost varied from 101 to 85 Euros $(P<0.001)$ per patient and year and HF medication mean cost from 86 to 90 Euros $(\mathrm{P}<0.001)$, respectively (Table 2$)$. The cumulative mean cost of diabetes medication and HF medication reached 486 and 417 Euros, respectively, in 2019 (supplementary Table 3 and Fig. 3). 
Table 2 Patients hospital mean cost for year ${ }^{a}$

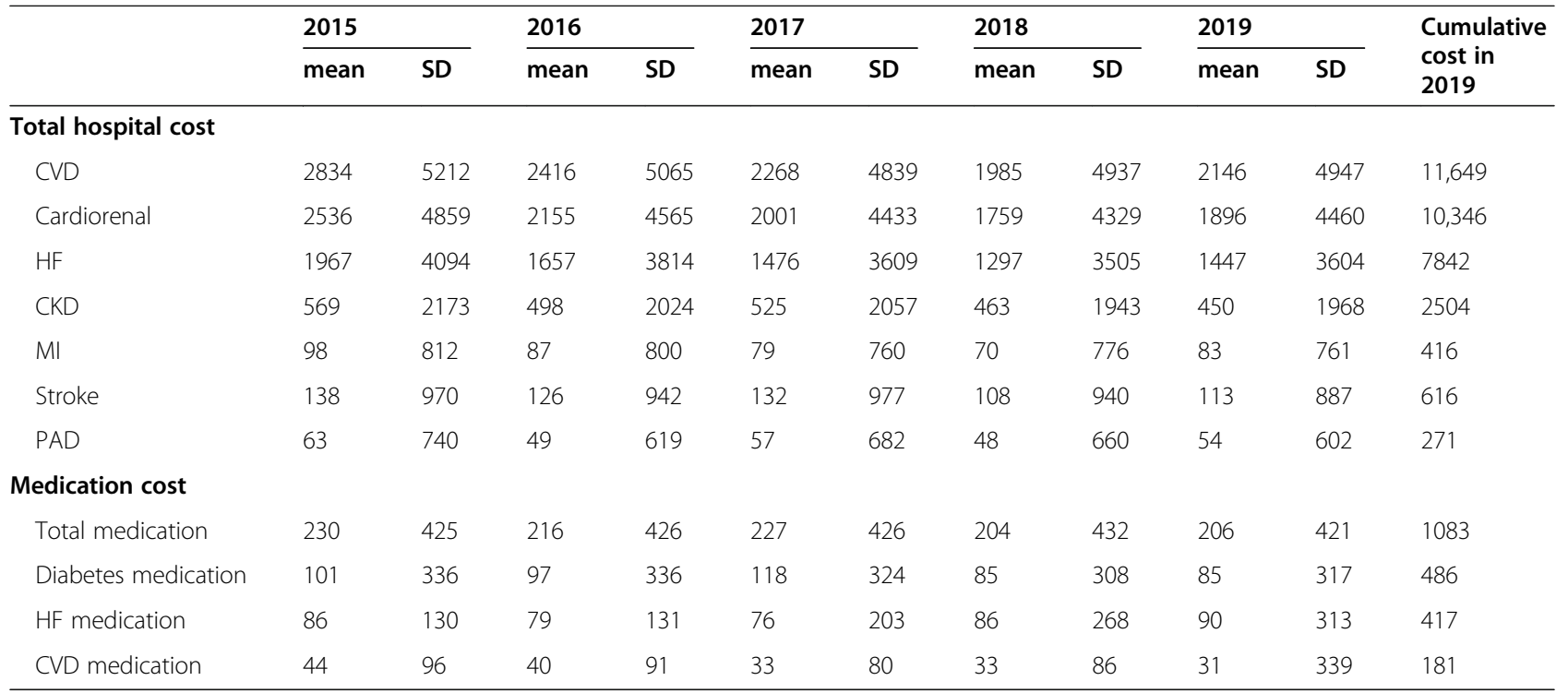

CVD Cardiovascular disease, HF Heart failure, CKD Chronic kidney disease, cardiorenal HF and/or CKD, MI Myocardial infarction, PAD Peripheral artery disease ${ }^{\mathrm{a}}$ In Euros

The health resources use for each year, including primary care visits, specialized visits, emergency rooms visits, hospitalization and diagnostic tests, was shown in Table 3. The proportion of hospitalized patients decreased from $31.5 \%$ in 2015 to $22.9 \%$ in $2019(P<0.001)$, the days for hospitalized patients due to HF from 8.3 to 7.2 days $(\mathrm{P}<0.001)$, and the proportion of patients that died from 9.4 to $4.9 \%(\mathrm{P}<0.001)$, respectively. Total sanitary cost decreased from 3700 Euros in 2015 to 2770 Euros in 2019 ( $\mathrm{P}<0.001)$. Including indirect costs, total cumulative patient mean costs reached 15,373 Euros in 2019, 263,852,978 Euros per total HF population (Table 4).

A specific analysis was performed in the DAPA-HF like population $(n=3178)$. In this subpopulation, mean age was $76.9 \pm 11.7$ years, $51.4 \%$ were men, and all patients had reduced left ventricular ejection fraction $\mathrm{HF}$

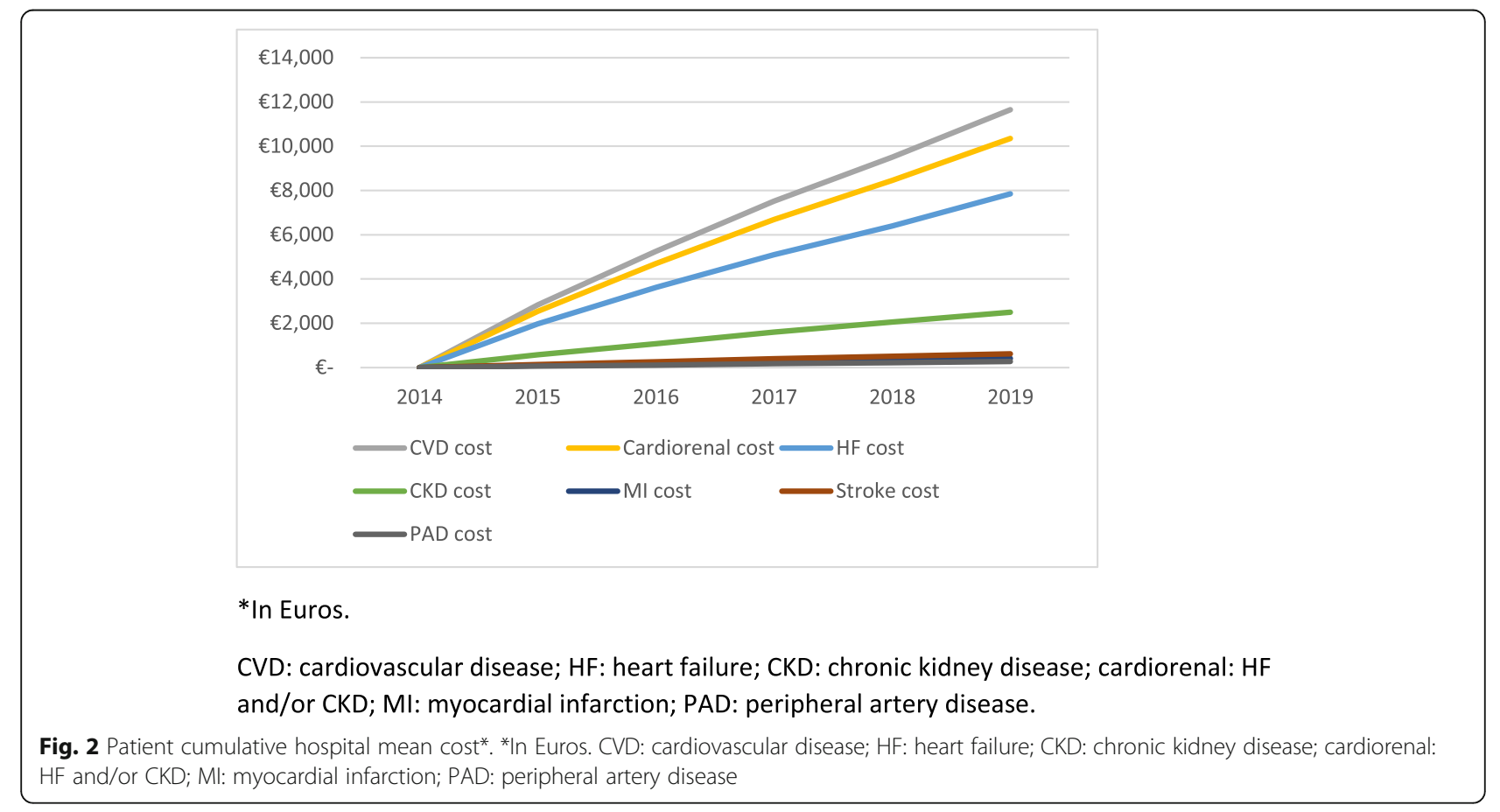




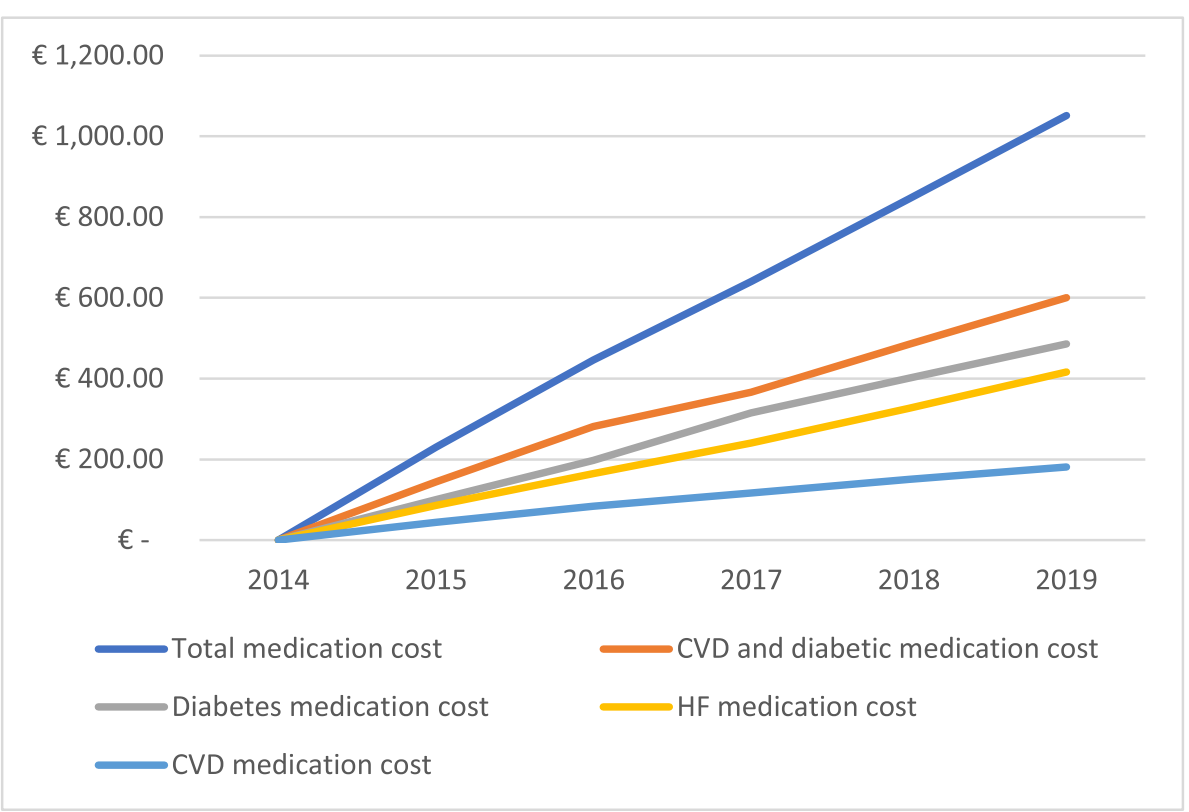

\section{*In Euros.}

CVD: cardiovascular disease; HF: heart failure.

Fig. 3 Patient cumulative medication mean cost*. ${ }^{*}$ In Euros. CVD: cardiovascular disease; HF: heart failure

Table 3 Health resources use for each year per patient

\begin{tabular}{|c|c|c|c|c|c|c|c|c|c|c|}
\hline & \multicolumn{2}{|l|}{2015} & \multicolumn{2}{|l|}{2016} & \multicolumn{2}{|l|}{2017} & \multicolumn{2}{|l|}{2018} & \multicolumn{2}{|l|}{2019} \\
\hline & mean & SD & mean & SD & mean & SD & mean & SD & mean & SD \\
\hline Primary care visits, mean (SD) & 12.7 & 15.0 & 10.9 & 14.2 & 9.6 & 13.9 & 8.8 & 14.3 & 7.7 & 13.0 \\
\hline Laboratory requests, mean (SD) & 0.6 & 1.2 & 0.6 & 1.2 & 0.6 & 1.2 & 0.7 & 1.6 & 1.0 & 2.1 \\
\hline Radiology and other tests, mean (SD) & 0.6 & 1.2 & 0.6 & 1.2 & 0.6 & 1.2 & 0.7 & 1.6 & 1.0 & 2.2 \\
\hline Specialized visits, mean (SD) & 2.1 & 4.2 & 1.3 & 4.9 & 1.1 & 4.8 & 1.2 & 4.9 & 1.1 & 4.8 \\
\hline Emergency rooms visits, mean (SD) & 0.8 & 2.5 & 0.7 & 3.3 & 0.7 & 3.1 & 0.5 & 2.3 & 0.5 & 3.3 \\
\hline \multicolumn{11}{|l|}{ Hospitalization } \\
\hline Days, mean (SD) & 5.9 & 10.8 & 5.0 & 10.5 & 4.7 & 10.0 & 4.1 & 10.3 & 4.5 & 10.3 \\
\hline Hospitalized patients, n (\%) & \multicolumn{2}{|c|}{$5399(31.5)$} & \multicolumn{2}{|c|}{$4557(26.6)$} & \multicolumn{2}{|c|}{$4227(24.6)$} & \multicolumn{2}{|c|}{$3628(21.1)$} & \multicolumn{2}{|c|}{$3923(22.9)$} \\
\hline Days for hospitalized patients due to heart failure only, mean (SD) & 8.3 & 10.7 & 7.7 & 10.6 & 7.5 & 10.1 & 6.9 & 10.1 & 7.2 & 10.2 \\
\hline \multicolumn{11}{|l|}{ Frequency of hospitalization, n (\%) } \\
\hline 0 & \multicolumn{2}{|c|}{$11,764(68.5)$} & \multicolumn{2}{|c|}{$12,606(73.5)$} & \multicolumn{2}{|c|}{$12,936(75.4)$} & \multicolumn{2}{|c|}{$13,535(78.9)$} & \multicolumn{2}{|c|}{$13,240(77.1)$} \\
\hline 1 & \multicolumn{2}{|c|}{$4243(24.7)$} & \multicolumn{2}{|c|}{$3565(20.8)$} & \multicolumn{2}{|c|}{$3225(18.8)$} & \multicolumn{2}{|c|}{$2780(16.2)$} & \multicolumn{2}{|c|}{$2914(17.0)$} \\
\hline 2 & \multicolumn{2}{|c|}{$1001(5.8)$} & \multicolumn{2}{|c|}{$855(5.0)$} & \multicolumn{2}{|c|}{$867(5.1)$} & \multicolumn{2}{|c|}{$724(4.2)$} & \multicolumn{2}{|c|}{$850(5.0)$} \\
\hline $3+$ & \multicolumn{2}{|c|}{$156(0.9)$} & \multicolumn{2}{|c|}{$137(0.8)$} & \multicolumn{2}{|c|}{$137(0.8)$} & \multicolumn{2}{|c|}{$124(0.7)$} & \multicolumn{2}{|c|}{$160(0.9)$} \\
\hline \multicolumn{11}{|l|}{ Disability } \\
\hline Days of disability, mean (SD) & 0.4 & 5.9 & 0.4 & 6.0 & 0.6 & 10.9 & 0.4 & 5.7 & 0.4 & 5.1 \\
\hline Patients with disability, n (\%) & $158(0$ & & $132(0$ & & $134(0$ & & $140(0$ & & $190(1$ & \\
\hline Average days of sick leave (disability only), mean (SD) & 43.8 & 43.5 & 47.4 & 49.5 & 77.2 & 96.9 & 50.5 & 38.5 & 36.7 & 32.6 \\
\hline Mortality, n (\%) & 1608 & & 1259 & & $927(5$ & & $893(5$ & & $839(4$. & \\
\hline
\end{tabular}


Table 4 Patients total mean cost for year and cumulative cost in 2019

\begin{tabular}{|c|c|c|c|c|c|c|c|c|c|c|c|}
\hline & \multicolumn{2}{|l|}{2015} & \multicolumn{2}{|l|}{2016} & \multicolumn{2}{|l|}{2017} & \multicolumn{2}{|l|}{2018} & \multicolumn{2}{|l|}{2019} & \multirow{2}{*}{$\begin{array}{l}\text { Cumulative } \\
\text { cost in } \\
2019\end{array}$} \\
\hline & mean & SD & mean & SD & mean & SD & mean & SD & mean & SD & \\
\hline Cost of primary care visits & 308 & 362 & 264 & 344 & 231 & 336 & 214 & 345 & 186 & 315 & 1202 \\
\hline Cost of laboratory requests & 20 & 39 & 19 & 38 & 18 & 37 & 24 & 50 & 32 & 69 & 113 \\
\hline Cost of radiology and other tests & 24 & 46 & 22 & 45 & 21 & 45 & 28 & 59 & 37 & 80 & 131 \\
\hline Cost of specialized visits & 195 & 392 & 123 & 467 & 108 & 451 & 108 & 462 & 101 & 452 & 635 \\
\hline Cost of emergency rooms visits & 89 & 291 & 81 & 394 & 79 & 363 & 57 & 276 & 61 & 382 & 368 \\
\hline Cost of Hospitalization & 2834 & 5212 & 2416 & 5065 & 2268 & 4839 & 1985 & 4937 & 2146 & 4947 & 11,649 \\
\hline Cost of medication & 230 & 425 & 216 & 426 & 227 & 426 & 204 & 432 & 206 & 421 & 1083 \\
\hline Sanitary Cost & 3700 & 5623 & 3141 & 5516 & 2920 & 5347 & 2620 & 5153 & 2770 & 5181 & 15,151 \\
\hline Indirect Cost/Sick Leave & 41 & 597 & 37 & 606 & 61 & 1.104 & 42 & 578 & 41 & 520 & 222 \\
\hline Total Cost & 3741 & 5665 & 3178 & 5553 & 2981 & 5482 & 2662 & 5202 & 2811 & 1276 & 15,373 \\
\hline
\end{tabular}

${ }^{\mathrm{a}}$ In Euros

(mean left ventricular ejection fraction $34.5 \pm 7.9 \%$ ). The majority of patients were on NYHA functional class II $(52.1 \%)$ or III $(43.0 \%)$. A total of $1314(41.3 \%)$ patients had T2D. With regard HF medication, $77.0 \%$ of patients were taking renin angiotensin system inhibitors, $100 \%$ beta blockers, $21.0 \%$ aldosterone antagonists, and 8.8\% sacubitril/valsartan. Compared with patients without diabetes, those patients with $\mathrm{T} 2 \mathrm{D}$ were taking more renin angiotensin system inhibitors, aldosterone antagonists and sacubitril/valsartan (supplementary Table 4).

With regard to patients hospital mean cost for year for this subpopulation, there was a progressive decrease of cardiovascular disease hospital cost per year (from 3269.6 Euros in 2015 to 2539.5 Euros in 2019, $P<$ 0.001). Overall, patient cumulative cardiovascular disease hospital mean cost reached 13,775 Euros in 2019. The great burden for this cost was due to cardiorenal hospitalizations $(87.7 \%$ of the total hospital cost), particularly HF $(65.9 \%$ of the total hospital cost). With regard to medication, from 2015 to 2019, diabetes medication mean cost decreased from 128.5 to 74.6 Euros $(\mathrm{P}<$ $0.001)$ and HF medication mean cost from 112.9 to 74.7 Euros $(\mathrm{P}<0.001)$, respectively. The cumulative mean cost of diabetes medication and HF medication reached 540 and 514 Euros, respectively, in 2019 (supplementary Table 5).

\section{Discussion}

Our study showed that in Spain, during the 2015-2019 period HF associated costs were high (patient total cost of 15,373 Euros), being cardiovascular hospitalizations the most important determinant (75.8\%), particularly HF hospitalizations (51.0\%). Total medication cost accounted for $7 \%$ of the total HF cost. In addition, the annual cardiovascular hospitalization mean cost progressive decreased over time.

In our study, the prevalence of HF was about $1.8 \%$. With regards to the HF population, mean age was 77 years, around half of patients had systolic HF, the majority of patients were on NYHA functional class II or III, one third had diabetes and comorbidities were common. In Spain, the studies performed in different clinical settings (hospital and outpatients) show a higher prevalence of HF [23]. However, the population-based studies reported similar numbers to our study [24]. The proportion of patients with systolic HF, as well as the presence of numerous comorbidities are in line with previous studies $[5,24]$. As a result, our study can be considered fairly representative of the Spanish population.

With regards to HF therapies, approximately two thirds of patients were taking renin angiotensin system inhibitors and beta blockers, nearly one third aldosterone antagonists, and only $8.5 \%$ sacubitril/valsartan. The optimization of treatment of patients with HF is necessary not only to improve functional class and quality of life, but also to reduce morbidity and mortality $[1,2]$. These numbers are lower than those reported in HF units, but in line with those from other clinical settings $[25,26]$. This is very relevant, as the underuse of evidence-based HF medication is associated with a higher use of healthcare resources, particularly first and recurrent hospitalizations [27].

During the period 2015-2019, patient cumulative cardiovascular disease hospital mean cost reached 11,649 Euros. Importantly, cardiorenal hospitalizations were the most important contributor for the total cost, particularly HF hospitalizations. Overall, HF hospitalizations represent $1-2 \%$ of total admissions $[7,28]$ and HF is the most common diagnosis in elderly hospitalized patients [29]. During the first year after diagnosis of HF, approximately half of the patients may be expected to be hospitalized at least once. In addition, readmission rates are high [7, 30-32]. Importantly, it has been reported that in Spain, rates of first hospitalization due to HF continue to increase, with high mortality [32]. A recent systematic review analyzed 16 cost-of-illness studies related to HF. 
Although there were large variations concerning cost components, the majority of them showed that hospital admission costs were the most expensive cost element. Annual costs for HF patients ranged from 868 Dollars $(\approx 774$ Euros) for South Korea to 25,532 Dollars ( $\approx 22,760$ Euros) for Germany [3]. Other systematic review focused on economic HF burden also showed that hospitalization cost was found to be the main cost driver to the total health care cost and that the HF annual cost ranged from 908 Dollars ( $\approx 809$ Euros) to 40,971 Dollars ( $\approx 36,522$ Euros) per patient [12]. In our study, during the 2015-2019 period, HF associated costs per patient reached 15,373 Euros, in line with these studies. However, among other factors, methodological heterogeneity and specific cost items (including treatments) accounted for in the estimations indicate that cost comparisons across publications should be made with caution [33]. Certainly, all these data confirm the high cost burden of HF. Some factors such as age, renal function, blood pressure, NYHA functional class, diabetes, body mass index, or medication/diet nonadherence have been associated with a higher morbidity and mortality. Therefore, since HF hospitalization is the main driver for HF costs, the early identification of these patients is mandatory, as these patients require a more careful follow-up and a greater intensification of treatment, in order to reduce HF burden [34, 35].

As the most important contributor for HF cost is HF hospitalizations, the use of those drugs that have demonstrated to be beneficial in this clinical context may be very helpful in reducing total HF cost. Thus, in 2014 the PARADIGM-HF trial showed that compared with enalapril, sacubitril/valsartan significantly reduced the risk of HF hospitalization by $21 \%$ and this might have had a positive impact [9]. In our study, from 2015 to 2019, in general there was a progressive reduction of cardiovascular disease hospital cost per year, as the proportion of hospitalized patients decreased. Interestingly, there was only a slight increase in HF medication cost per year which is a small contributor for total HF cost. This is in line with previous studies that have shown a decline in standardized HF hospitalization rates in Europe and United States [36, 37]. However, absolute numbers of HF hospital admissions are expected to increase by about $50 \%$ in the following years due to the ageing of the population [7]. As a result, new drugs are needed to improve these numbers. In 2019, the DAPA-HF trial showed that in addition to recommended therapy, dapagliflozin significantly reduced the risk of a first worsening HF event by 30\% [10]. Therefore, it can be hypothesized the addition of dapagliflozin to standard HF therapy may contribute to reduce HF costs.

Other contributors to total HF cost included primary care visits, specialized visits, and diagnostic tests. It has been reported that a better integrated hospital primary care HF program is associated with a significant reduction of readmission for $\mathrm{HF}$ and mortality [38]. In addition, moving to case management at home rather than outpatient cardiology clinic follow-up may also reduce healthcare costs [39]. Therefore, transition to an integrated management of HF patients is necessary to reduce HF burden.

A recent meta-analysis estimated the one, two, five and 10 -year survival to be $87,73,57$ and $35 \%$, respectively, among HF patients [40]. HF hospitalization is an independent predictor for increased HF mortality [7, 30, 31]. In our study the proportion of patients who died decreased from $9.4 \%$ in 2015 to $4.9 \%$ in 2019 , in line with the decrease in hospitalization rates. Although there is much room for progress, it is likely that the improvement in HF management during these years may have had a positive impact.

A specific analysis was performed in the DAPA-HF like population. In the DAPA-HF trial, the addition of dapagliflozin resulted in a significant reduction of $\mathrm{HF}$ hospitalizations, death from cardiovascular causes, and death from any cause, regardless the presence of diabetes [10]. In our study, in the DAPA-HF like population, all patients had reduced left ventricular ejection fraction HF and the majority of patients were on NYHA functional class II or III. Compared with the overall HF population, patients were taking more renin angiotensin system inhibitors and beta blockers. Although in these patients there was a decrease of patients hospital mean cost for year, these were higher than in the overall HF population. Thus, cumulative cardiovascular disease hospital cost reached 13,775 Euros (vs 11,649 Euros in the overall HF population). The great burden for this cost was due to cardiorenal hospitalizations $(87.7 \%$ of the total hospital cost), particularly HF (65.9\% of the total hospital cost). Therefore, to reduce HF cost burden in the DAPA-HF like population is of utmost importance to improve the HF management. As the great majority of these patients were taking renin angiotensin system inhibitors and beta blockers, the prescription of newer HF drugs, such as dapagliflozin, could be of particular benefit in the reduction of HF costs [10]. In fact, a recent study has shown that dapagliflozin may be a costeffective treatment for HF patients in not only in United Kingdom and Germany, but also Spain [41].

This study has some limitations that should be commented. This was an observational cohort study that used secondary data from electronic health records. In addition, there were certain factors, such as some clinical characteristics that could not be controlled. As a result, variations in healthcare costs can not only be related with modifications in the prescription of HF drugs. Therefore, only indirect causality can be provided. 
However, the high number of patients included, as well as the robustness of the data may allow to determine the value of the study. On the other hand, although data came from seven Spanish regions, previous studies have shown that these data are representative of the Spanish population [19].

\section{Conclusion}

During the 2015-2019 period, costs of patients with HF in Spain were high, being cardiovascular hospitalizations the most important determinant, particularly HF hospitalizations. Medication costs were responsible for only a small proportion of total HF costs. Costs and healthcare resources use were even higher in the DAPA-HF like population. Improving HF management, particularly through the use of those drugs that reduce HF hospitalization may be helpful to reduce HF burden.

\section{Supplementary information}

Supplementary information accompanies this paper at https://doi.org/10. 1186/s12913-020-05828-9.

Additional file 1: Table S1. Definition of variables.

Additional file 2: Table S2. Description of costs / units (year 2019).

Additional file 3: Table S3. Patient cumulative hospital mean cost*.

Additional file 4: Table S4. Baseline clinical characteristics of the DAPA-HF population according to the presence of type 2 diabetes.

Additional file 5: Table S5. DAPA-HF patients hospital mean cost for year and cumulative cost in 2019*.

\section{Abbreviations}

HF: Heart failure; T2D: Type 2 diabetes

\section{Acknowledgements}

None.

\section{Authors' contributions}

$C E, L V, B P, M C, A S, A S, A H, R A, N M$ and $M B$ have contributed to the study design, result review and manuscript preparation and have approved the submitted version.

\section{Funding}

Ths study was fully funded by AstraZeneca. The funding body played no role in the design of the study and collection, analysis, and interpretation of data and in writing the manuscript.

\section{Availability of data and materials}

This was a secondary data study using BIG PAC ${ }^{\circledR}$ database. Public access to the database is open.

\section{Ethics approval and consent to participate}

This study was approved by the Investigation Ethics Committee of Consorci Sanitari from Terrassa on 16th December 2019. This was a secondary data study and data were fully anonymized and dissociated from patients. Therefore, there was no need for providing informed consent in Spain.

\section{Consent for publication}

Not applicable.

\section{Competing interests}

None.

\section{Author details}

${ }^{1}$ University Hospital La Paz, Madrid, Spain. ${ }^{2}$ AstraZeneca Spain, Barcelona, Spain. ${ }^{3}$ Health Economics and Outcomes Research, Atrys Health, Barcelona, Spain. ${ }^{4}$ Primary Care Center Salud Puerta Blanca, Malaga, Spain. ${ }^{5}$ University Hospital Infanta Leonor, Madrid, Spain. ${ }^{6}$ Hospital de Bellvitge, Hospitalet de Llobregat, Barcelona, Spain. ${ }^{7}$ Hospital Universitario Lucus Augusti, Lugo, Spain

Received: 29 July 2020 Accepted: 15 October 2020

Published online: 20 October 2020

\section{References}

1. Yancy CW, Jessup M, Bozkurt B, et al. 2017 ACC/AHA/HFSA focused update of the 2013 ACCF/AHA guideline for the Management of Heart Failure: a report of the American College of Cardiology/American Heart Association task force on clinical practice guidelines and the Heart Failure Society of America. Circulation. 2017;136:e137-61.

2. Ponikowski P, Voors AA, Anker SD, et al. 2016 ESC guidelines for the diagnosis and treatment of acute and chronic heart failure. Eur Heart J. 2016:37(27):2129-200.

3. Lesyuk W, Kriza C, Kolominsky-Rabas P. Cost-of-illness studies in heart failure: a systematic review 2004-2016. BMC Cardiovasc Disord. 2018;18(1):74.

4. van Riet EE, Hoes AW, Wagenaar KP, Limburg A, Landman MA, Rutten FH. Epidemiology of heart failure: the prevalence of heart failure and ventricular dysfunction in older adults over time. A systematic review. Eur J Heart Fail. 2016:18:242-52.

5. Sayago-Silva I, García-López F, Segovia-Cubero J. Epidemiology of heart failure in Spain over the last 20 years. Rev Esp Cardiol (Engl Ed). 2013;66: 649-56.

6. Conde-Martel A, Hernández-Meneses M. Prevalence and prognostic meaning of comorbidity in heart failure. Rev Clin Esp. 2016;216:222-8.

7. Groenewegen A, Rutten FH, Mosterd A, Hoes AW. Epidemiology of heart failure [published online ahead of print, 2020 Jun 1]. Eur J Heart Fail. 2020. https://doi.org/10.1002/ejhf.1858.

8. Pocock SJ, Ariti CA, McMurray JJ, et al. Predicting survival in heart failure: a risk score based on 39,372 patients from 30 studies. Eur Heart J. 2013;34(19): 1404-13.

9. McMurray JJ, Packer M, Desai AS, et al. Angiotensin-neprilysin inhibition versus enalapril in heart failure. N Engl J Med. 2014;371:993-1004.

10. McMurray JJV, Solomon SD, Inzucchi SE, et al. Dapagliflozin in patients with heart failure and reduced ejection fraction. N Engl J Med. 2019;381(21): 1995-2008.

11. Lee $\mathrm{H}, \mathrm{Oh} \mathrm{SH}, \mathrm{Cho} \mathrm{H}, \mathrm{Cho} \mathrm{HJ}$, Kang HY. Prevalence and socio-economic burden of heart failure in an aging society of South Korea. BMC CardiovasC Disord. 2016;16(1):215.

12. Shafie AA, Tan YP, Ng CH. Systematic review of economic burden of heart failure. Heart Fail Rev. 2018;23(1):131-45.

13. Romero-González G, Ravassa S, González O, et al. Burden and challenges of heart failure in patients with chronic kidney disease. A call to action. Nefrologia. 2020;40(3):223-36.

14. Merino $M$, Jiménez $M$, Manito $N$, et al. The social return on investment of a new approach to heart failure in the Spanish National Health System. ESC Heart Fail. 2020;7(1):130-7.

15. Hernández-Madrid A, Lu X, Tsintzos SI, et al. Heart failure hospitalization reduction and cost savings achieved by improved delivery of effective biventricular pacing: economic implications of the OLE study under the US setting. Clinicoecon Outcomes Res. 2019;11:385-93.

16. Cainzos-Achirica M, Capdevila C, Vela E, et al. Individual income, mortality and healthcare resource use in patients with chronic heart failure living in a universal healthcare system: a population-based study in Catalonia, Spain. Int J Cardiol. 2019;277:250-7.

17. Manito Lorite N, Rubio-Rodríguez D, González Costello J, et al. Economic analysis of intermittent intravenous outpatient treatment with levosimendan in advanced heart failure in Spain. Rev Esp Cardiol (Engl Ed). 2020;73(5):361-7.

18. Delgado JF, Oliva J, Llano M, et al. Health care and nonhealth care costs in the treatment of patients with symptomatic chronic heart failure in Spain. Rev Esp Cardiol (Engl Ed). 2014;67(8):643-50.

19. Sicras-Mainar A, Enríquez JL, Hernández I, Sicras-Navarro A, Aymerich T, León M. Validation and representativeness of the Spanish BIG-PAC database: integrated computerized medical records for research into epidemiology, 
medicines and health resource use (Real Word Evidence). Value Health. 2019;22(Supplement 3):S734.

20. The Anatomical Therapeutic Chemical Classification System with Defined Daily Doses (ATC/DDD): World Health Organization. Available at: https:// www.who.int/classifications-/atcddd/en/. Last Accessed: 10 June 2020.

21. General Council of Official Pharmacists' Colleges of Spain. Available at: https://botplusweb.portalfarma.com.

22. Statistics National Institute. 2017. Average labor profit according to age and gender. Accessed: 10 May 2020 Available at: https:/www.ine.es/dynt3/ inebase/index.htm?padre $=4563 \&$ capsel $=4563$.

23. Anguita Sánchez $M$, Crespo Leiro MG, de Teresa GE, Jiménez Navarro M, Alonso-Pulpón L, Muñiz García J, PRICE Study Investigators. Prevalence of heart failure in the Spanish general population aged over 45 years. The PRICE Study. Rev Esp Cardiol. 2008;61:1041-9.

24. Farré $\mathrm{N}$, Vela $\mathrm{E}$, Clèries $\mathrm{M}$, et al. Real world heart failure epidemiology and outcome: a population-based analysis of 88,195 patients. PLoS One. 2017;12: e0172745.

25. Crespo-Leiro MG, Segovia-Cubero J, González-Costello J, et al. Project research team.. Adherence to the ESC heart failure treatment guidelines in Spain: ESC heart failure long-term registry. Rev Esp Cardiol. 2015;68:785-93.

26. Greene SJ, Butler J, Albert NM, DeVore AD, Sharma PP, Duffy Cl, et al. Medical therapy for heart failure with reduced ejection fraction: the CHAMP-HF registry. J Am Coll Cardiol. 2018;72:351-66.

27. Sicras Mainar A, Navarro Artieda R, Ibáñez NJ. Economic impact of heart failure according to the effects of kidney failure. Rev Esp Cardiol. 2015;68: $39-46$.

28. Alla F, Zannad F, Filippatos G. Epidemiology of acute heart failure syndromes. Heart Fail Rev. 2007;12:91-5.

29. Braunwald E. The war against heart failure: the lancet lecture. Lancet. 2015; 385:812-24.

30. Nichols GA, Reynolds K, Kimes TM, Rosales AG, Chan WW. Comparison of risk of re-hospitalization, all-cause mortality, and medical care resource utilization in patients with heart failure and preserved versus reduced ejection fraction. Am J Cardiol. 2015;116:1088-92.

31. Shah $\mathrm{KS}, \mathrm{Xu}$ H, Matsouaka RA, et al. Heart failure with preserved, borderline, and reduced ejection fraction: 5-year outcomes. J Am Coll Cardiol. 2017;70: 2476-86.

32. Fernández-Gassó L, Hernando-Arizaleta L, Palomar-Rodríguez JA, AbellánPérez MV, Hernández-Vicente Á, Pascual-Figal DA. Population-based Study of First Hospitalizations for Heart Failure and the Interaction Between Readmissions and Survival. Rev Esp Cardiol (Engl Ed). 2019;72:740-8.

33. Oliva J, Jorgensen N, Rodríguez JM. Carga socioeconómica de la insuficiencia cardíaca: revisión de los estudios de coste de la enfermedad. Pharmacoecon Span Res Artic. 2010;7:68-79.

34. Rahimi K, Bennett $\mathrm{D}$, Conrad N, et al. Risk prediction in patients with heart failure: a systematic review and analysis. JACC Heart Fail. 2014;2(5):440-6.

35. Ambrosy AP, Fonarow GC, Butler J, et al. The global health and economic burden of hospitalizations for heart failure: lessons learned from hospitalized heart failure registries. J Am Coll Cardiol. 2014;63(12):1123-33.

36. Schmidt M, Ulrichsen SP, Pedersen L, Bøtker HE, Sørensen HT. Thirty-year trends in heart failure hospitalization and mortality rates and the prognostic impact of co-morbidity: a Danish nationwide cohort study. Eur J Heart Fail. 2016;18:490-9.

37. Ziaeian B, Kominski GF, Ong MK, Mays VM, Brook RH, Fonarow GC. National differences in trends for heart failure hospitalizations by sex and race/ ethnicity. Circ Cardiovasc Qual Outcomes. 2017;10:e003552.

38. Comín-Colet J, Verdú-Rotellar JM, Vela E, et al. Efficacy of an integrated hospital-primary care program for heart failure: a population-based analysis of 56,742 patients. Rev Esp Cardiol (Engl Ed). 2014:67(4):283-93.

39. van Voorst $H$, Arnold AER. Cost and health effects of case management compared with outpatient clinic follow-up in a Dutch heart failure cohort. ESC Heart Fail. 2020;7(3):1136-44.

40. Jones NN, Roalfe AK, Adoki I, Hobbs FD, Taylor CJ. Survival of patients with chronic heart failure in the community: a systematic review and metaanalysis. Eur J Heart Fail. 2019;21:1306-25.

41. McEwan P, Darlington O, McMurray JJV, et al. Cost-effectiveness of dapagliflozin as a treatment for heart failure with reduced ejection fraction: a multinational health-economic analysis of DAPA-HF. Eur J Heart Fail. 2020. Epub ahead of print. https://doi.org/10.1002/ejhf.1978.

\section{Publisher's Note}

Springer Nature remains neutral with regard to jurisdictional claims in published maps and institutional affiliations.
Ready to submit your research? Choose BMC and benefit from:

- fast, convenient online submission

- thorough peer review by experienced researchers in your field

- rapid publication on acceptance

- support for research data, including large and complex data types

- gold Open Access which fosters wider collaboration and increased citations

- maximum visibility for your research: over $100 \mathrm{M}$ website views per year

At BMC, research is always in progress.

Learn more biomedcentral.com/submissions 